\title{
The Advantages and Disadvantages of Learning a Second Language Early
}

\author{
Chenxu Zhang* \\ No.99 South Third Ring Road (Donghu Campus), Changshu 215500, Jiangsu, China \\ *Corresponding author.Email: z07119221@cslg.edu.cn
}

\begin{abstract}
With the accelerating of the worldwide favor of learning a second language, this article illustrates the advantages and disadvantages of learning a second language early by analysing relevant research and articles. The advantages of learning a second language are based on the prefrontal cortex in the brain that can help promote the cognitive development like attentional ability, memory and creativity. The acquisition of a second language can in fact benefit from the cognitive development and the academic development. In contrast, learning a second language too early can lead to a loss of the native language and the inadequate mastery of native language makes it more difficult to learn a foreign language. Academic burden and external factor such as the lack of proper education can hinder the secondlanguage-process as well.
\end{abstract}

Keywords: cognitive development, influence of age, academic performance, effect of native language, uneven education.

\section{INTRODUCTION}

As time goes on, globalization will continue to accelerate the intensification of worldwide social relations which link distant localities in such a way that local happenings are shaped by events occurring many miles away and vice versa [1]. Language is important in globalization because it serves as a channel for interactions between people and spaces while it is also influenced by global influences. Hence, to integrate into the globalization process, there is a boom in learning a new language today to communicate with people in different countries and areas. There are many advantages for people to be bilingual or multilingual: 1) Switching between languages is essentially a form of brain training. Mentally regulating two or more languages gives the brain cognitive benefits and leads to higher degree of metalinguistic awareness, similar to how regular physical training improves the body medically [2]. 2) Language learning can also make you a better person. Language learning improves one's ability to empathize, or see a situation from another's point of view, according to social studies. When you learn a new language, you not only pick up new words and sounds, but you also pick up new thoughts. It's as if you're looking at the world through various lenses [3]. 3) Language abilities might also help you get work and increase your international trade opportunities. Languages are an essential aspect of the 21st century skill set in an increasingly multicultural and multilingual employment environment [4]. Language abilities may not guarantee employment in itself, but they can give you an edge over a monolingual candidate. 4) If you're looking to buy something, English is good, but it might not be the best language to use if you want to sell anything [5]. According to government statistics, the UK loses roughly 3.5 percent of its GDP each year due to a lack of language skills in the workforce. In a globalized economy, other countries, on the other hand, can use their multilingualism as a resource with exchange value. The economic worth of multilingualism in Switzerland, for example, is estimated to gain $10 \%$ of GDP because many Swiss enterprises can readily operate in multiple languages [6]. With so many advantages, learning a second language has become a popular option for many people and families.

In a case of learning a second language, however, recently the issue that should students learn a second language at a young age has attracted people. For example, there are numerous advantages and disadvantages that children have when learning English as a foreign language in order to become bilinguals [7]. Some people think that learning a second language has a significant advantage in that it teaches youngsters to 
focus their attention on the important variables in the context, including ambiguous or contradictory information. Increased cognitive capacities may aid in the development of the skills thought to be involved in effective communication in youngsters. Knowing two words that describe the same notion, such as "good" and "great," for example, can help children realize that an object or event can be described in multiple ways, which can aid their understanding of other people's viewpoints. "Research has proven that the brain interprets language differently after 10 or 12 years old since it is constantly building neural connections till then. The frontal lobe of the brain is where we process language as children. When we acquire a language as a teenager or adult. However, the brain has to 'scramble' to locate new storage space. In basic terms, when you learn a language as a youngster, your brain absorbs it quickly; after that, it takes a lot more effort" [8]. Plus, learning a second language early can help students have better academic development. On standardized tests administered in English, students who speak a second language perform statistically better. The College Entrance Examination Board reported in its 1992 reportCollege Bound Seniors: the 1992 Profile of SAT and Achievement Test Takers, that students who had studied a foreign language for four years or more scored higher on the verbal section of the SAT than students who had studied four years or more in any other subject area. Furthermore, the average mathematics score for people who had studied a foreign language for four years or more was the same as for people who had studied mathematics for the same amount of years. In contrast, the other ones think that learning a second language has disadvantages for children. Bilingual children face several disadvantages when learning English as a foreign language. If children have been exposed to different languages since birth, they may begin speaking three to six months later than children who are raised in a monolingual environment will temporally mix languages [9]. Rehman says that "You can expect your bilingual child to begin speaking about 3-6 months later than his/her monolingual peers." Another significant disadvantage of learning a foreign language at a young age is that children will mix languages for a period of time. Another significant disadvantage of learning a foreign language at a young age is that children will mix languages for a period of time. "It is normal for bi/multilingual children to mix up languages until about the age of 4 . If children are lacking the right word in language $\mathrm{A}$, they will borrow it from language $\mathrm{B}$ to communicate their message". According to Rehman, it implies that individuals may mix languages at any time, influencing how they connect with others and transmit their ideas or messages.

The impact of ages on learning a second language is still not clear and convictive. To make it completer and more comprehensive, the purpose of this article is to analyse the advantages and disadvantages of learning a second language early by reviewing relevant articles and research in recent years.

\section{ADVANTAGES}

\subsection{Brain and cognitive development}

There are many theories that second language learning is closely related to the brain especially in the early stage. The prefrontal cortex in the brain plays an important role in it. Precisely, the development of prefrontal cortex is related to the cognitive development which is fundamental to the acquisition of language and other skills. According to Piaget [10], this ability develops in a predictable pattern through a sequence of well-defined phases and milestones. The kid, between the ages of 2 and 7, enters a representational stage of extended verbal symbolism after a first stage of rudimentary sensory-motor integration and primitive symbolization. External feedback, such as language from other people, gradually gets more complex and regulated. The youngster develops the ability to postpone gratification. From the ages of 7 to 11 , language and behavior become more structured, less reliant on external stimuli, and more inventive. Enter games, sports, erector sets, and problem-solving. These two stages in the Stage Theory shows us how the language learning other abilities improve as the development of cognition.

\subsection{Additional control ability}

Plus, the cognitive development can also be affected by the language acquisition. Children's frontal lobe functioning for controlling attention is affected by it too. The development of children's cognitive and neurological systems is influenced in part by their daily learning experiences, which include language acquisition. Children face a variety of linguistic and socio-linguistic circumstances during the course of language acquisition, all of which necessitate some form of conflict resolution, for example, adjudicate the meanings of similar sounding words like "I" and "eye" [11]. The doubling of these conflicting contexts that are typical of bilingual language acquisition (e.g., increasing the number of possible homophones) and the unique need to selectively attend to one language while suppressing the other, according to theories of bilingual cognitive development, may alter bilinguals' attentional control mechanisms [12][13][14][15]. The ability to deliberately focus and shift attention is known as attentional control [16]. In a standard word-image matching test, for example, participants take longer to choose a picture when they encounter photos with similar initial sounds such as "card" and "cart," versus "card" and "lion" [17]. Participants are faced with verbal interference throughout this exercise, which 
forces them to ignore the competing distractor. Importantly, bilingual participants' performance in this task can be influenced by both within-language and cross-language distractors. These findings demonstrate not only the attentional difficulties of language processing, but also the broader assumption that bilinguals' languages are frequently co-active [18][19]. The higher requirement for attentional control across various contexts of bilingual language usage, from word recognition to discourse, is hypothesized to result from such continual co-activation of bilinguals' two languages [15]. Thus, theories of bilingual development propose that early childhood bilingual exposure during periods of rapid brain development may result in earlyemerging and lifetime modifications in children's attentional control abilities [20].

\subsection{Other cognitive performances}

Besides the improvement of attentional control abilities, learning a second language can help children strengthen their memory, creativity and other cognitive performance. In contrast to the mixture between native language and second language, children can differentiate two different languages within the first weeks of life. "Learning another language actually enhances a child's overall verbal development," says Roberta Michnick Golinkoff, author of How Babies Talk. The study goes on to show that acquiring a second language at a young age has a number of other cognitive benefits. Children who study a foreign language outperform their peers in terms of overall basic skills in elementary school. They go on to score higher on SATs, according to the College Entrance Examination Board. Children who learn a foreign language at an early age have greater problem-solving abilities, improved spatial linkages, and increased creativity.

Learning a second language at a young age promotes flexible thinking and communication skills, allowing youngsters to approach challenges from multiple perspectives. Furthermore, studies demonstrate that multilinguals have better memory, planning, and multitasking abilities. When learning many languages as a child, the brain is educated to pay attention to key information and ignore irrelevant information, a skill that subsequently enables improved focus, memory, planning, and multitasking abilities. According to research, multilinguals employ more of their brains than monolinguals and outperform monolinguals in creativity tests [21].

\subsection{Academic development}

Another advantage of learning a second language early is that it can help kids obtain academic development. Recent research of the reading abilities of 134 four- and five-year-old children, for example, discovered that bilingual children grasped the broad symbolic representation of print better than monolingual children [22]. Another study examined achievement test results from kids in Fairfax County, Virginia, who had engaged in immersion, the most intensive sort of foreign language program, for five years. The study concluded that those students outperformed all comparison groups on achievement assessments and remained strong academic performers throughout their schooling [23]. Finally, a study conducted in Louisiana in the 1980s found that, regardless of race, gender, or academic level, students who received daily instruction in a foreign language (taught as a separate subject rather than through immersion) outperformed those who did not on the third-, fourth-, and fifth-grade language arts sections of Louisiana's Basic Skills tests [24].

All of these results suggest that second language study helps enhance English (native language) and other academic skills. According to several research, students who acquire foreign languages perform statistically better on standardized college entrance examinations than those who do not. For example, the College Entrance Examination Board reported that students who had averaged four or more years of foreign language study outperformed those who had studied four or more years of any other topic on the verbal component of the Scholastic Aptitude Test (SAT) [25].

\section{DISADVANTAGES}

\subsection{The influence of native language on the second language learning}

It can be learned from the above that age plays a key role in second language learning and younger language learners have many benefits from the acquisition of a second language. But whether learning a second language early facilitates the learning process remains unknown. As old as primary school and middle school students who have mastered their first language can do better in the acquisition of the second language. For example, Lightbown and Spada cite research conducted by Snow and Hoefnagel-Hohle on a group of English speakers learning Dutch as a second language [26]. This research was enlightening shed light on very useful because it included students of different ages, ranging from six to sixty years old. Surprisingly, this research found that teenagers, not children or adults, were by far the most successful learners. Snow and HoefnagelHohle discovered that young learners struggled with activities that were beyond their cognitive maturity, but adolescents acquired more quickly in the early phases of second language development. The study concludes that when adults and adolescents used their original language on a daily basis in social, professional, and academic interactions, they were able to make significant progress in native language learning [27]. 
According to the research, learners who have excellent academic skills in their home language will learn a second language faster than those who do not have similar skills in their native language. In other words, effective first-language acquisition is critical for learning a second language. According to the research, learners who have excellent academic skills in their home language will learn a second language faster than those who do not have similar skills in their native language.

\subsection{Learning a second language means impairing the use of the first one}

"Subtractive Bilingualism," the name given the problem by Wallace Lambert who first discussed it in relation to French-Canadian and Canadian immigrant children whose acquisition of English in school resulted not in bilingualism, but in the erosion or loss of their primary languages [28-30]. The phenomeon is wellknown in the United States. It is the narrative of numerous American immigrant and native children and adults who have lost their ethnic languages as a result of linguistic assimilating into the English-speaking environment of school and culture. Even if it was the only language they spoke when they first started school, few American-born children of immigrant parents are totally skilled in the ethnic language. Once young children have learned English, they are less likely to retain or develop the language spoken at home, even if it is the only language their parents know. This has been the tale of previous immigrant groups, and it is the story of today. The only difference is that the process appears to be moving much faster today [31].

\subsection{Learning a second language exerts pressure on kids and parents}

Another disadvantage is that bilingual children will have to deal with the additional academic load that comes with learning to read and write in another language on top of the first; this means that they will have to work twice as hard. If parents want their children to not only speak another language but also read and write it, they will need to provide extra instruction outside of regular school hours. Silke Rehman believes "Organizing language lessons requires considerable effort, both financially and in terms of time. However, all parents would agree that the advantages outweigh the effort." An additional academic burden or supplementary tuition, on the other hand, becomes boring and difficult for children. As a result, they prefer to engage in other types of activities, such as sports, and as a result, they decide to discontinue their bilingual education.

\subsection{External factors impede the process of learning a foreign language}

Furthermore, a variety of factors, including the circumstances in which the languages are learned, might influence the outcome of multilingual development. The context or environment is very crucial in the learning process of children. Furthermore, children should use every resource in their environment as a tool to benefit from and readily learn the language. Parents (family) and school are the most essential factors within the child's setting for success in becoming a bilingual child. However, there are a number of variables at school and at home that impede the process of learning a foreign language, such as ineffective attempts at integration into society, a shortage of teachers, a lack of classrooms, parents and teachers fluency in the foreign language, and so on. (www.everythingesl.net). 1) Unsuccessful attempts at integration into Society are one of the most serious issues confronting bilingual education in the United States. "Bilingual education was thought vital since it was meant to better integrate the children of immigrants and minorities into society," writes Aparna Iyer. The bilingual education system required distinct teachers and classrooms and believed in gradual integration into society by allowing children to receive instruction in their home language for three or more years." 2) The unavailability of teachers is also a factor which blocks the second language learning process on kids. For example, In El Salvador, public schools have only one English teacher for the entire student body. Furthermore, some teachers are not allocated in their area of specialization. An English instructor, for example, may be appointed to teach science or another topic, or vice versa. As a result, children are not receiving enough English education to become fluent in the language. It means that public schools are not interested in helping their children become multilingual, which is a significant disadvantage. Just as Aparna Lyer says that "Bilingual education requires a number of trained teachers who are proficient in both English and their native language, assuming that Spanish is one of the mediums of instruction" [32].

\section{CONCLUSION}

In this article, advantages and disadvantages of learning a second language are argued systematically. First of all, advantages of learning a second language are that the development of the prefrontal cortex is related to the cognitive language which can actually be beneficial to the acquisition of a second language. Secondly, cognitive development is also affected by the process of learning a second language such as attentional ability, memory and creativity which is increased as continuation of the second-languagelearning process. Thirdly, learning a second language helps kids obtain academic development to outperform 
those students in the same phase. In contrast, there are disadvantages of learning a second language early. To begin with, "the earlier to learn a second language is better" is wrong. In fact, effective native-language acquisition is crucial for learning a second one which means that it is not efficient enough for a kid who has not mastered his mother tongue to learn a second language. Moreover, learning a second language means impairing the use of the first one after analyzing the phenomenon in the United States that immigrant kids can lose their own languages after assimilating into the English-speaking environment. Plus, the burden on the family and kids themselves can lead them to lose the motivation and interests in acquiring a second language. In this case, the advantages outweigh the disadvantages. For the natural edge, kids should seize the opportunity to learn even to master a second language in their young age. The burdens and the education can be handled correctly with the help of parents and professional teachers. The native language and the second language should be treated equally as kids grow up to become bilingual. Not only because of the natural edge which kids have, but also the benefits that learning a second language brings, kids are supposed to learn a foreign language as early as possible.

\section{REFERENCES}

[1] Giddens (1990). The consequences of modernity. Cambridge, England: Polity

[2] K. Hakuta (1986). Cognitive Development of Bilingual Children. Paper presented at Centre for Language Education and Research University of California, Los Angeles

[3] T. Jones (2018). The Joys and Benefits of Bilingualism. Retrieved from https://www.theguardian.com/commentisfree/2018/ $\mathrm{jan} / 21 /$ the-joys-and-benefits-of-bilingualism

[4] E. Corradini, K. Borthwick, \& A. Gallagher-Brett (2016). Employability for languages: a handbook. Retrieved from https://files.eric.ed.gov/fulltext/ED566902.pdf

[5] M. Williams(2015). The Guardian. Retrieved from https://www.theguardian.com/education/2015/apr/1 4/seven-language-learning-uk-multilinguilism

[6] G. Hogan-Brun(2017). The Conversation. Retrieved from https://theconversation.com/whymultilingualism-is-good-for-economic-growth71851

[7] L. E. I. INGLES(2010). ADVANTAGES AND DISADVANTAGES THAT KIDS HAVE AT THE TIME THEY ARE LEARNING ENGLISH AS A FOREIGN LANGUAGE TO BECOME BILINGUAL.
[8] National Literacy Trust 2007 - Developing Language for Life

[9] Silke Rehman, 2010 Make Your Child Multilingual!: The 10 Step Success Plan to Raising Bilingual / Multilingual Children, Booksurge Llc.

[10] J. PIAGET (1952) The Origins of Intelligence in Children. New York: International Universities Press.

[11] R. Mazuka, R. Jincho,, \& H. Oishi, (2009). Development of executive control and language processing. Language and Linguistics Compass, 3, 59-89.

[12] E. Bialystok, F. I. M. Craik, \& G. Luk, (2012). Bilingualism: consequences for mind and brain. Trends in Cognitive Sciences, 16, 240-250.

[13] D. W. Green, \& J. Abutalebi, (2013). Language control in bilinguals: the adaptive control hypothesis. Journal of Cognitive Psychology, 25, 515-530.

[14] Y. Dong, \& P. Li, (2015). The cognition science of bilingualism. Language and Linguistics Compass, 9, 1-13.

[15] J. F. Kroll, P. E. Dussias, K. Bice, \& L. Perrotti, (2015). Bilingualism, mind, and brain. Annual Review of Linguistics, 1, 377-394.

[16] M. I. Posner,(2012). Attention in a Social World. UK: Oxford University Press

[17] V. Marian, \& M. Spivey (2003). Bilingual and monolingual processing of competing lexical items. Applied Linguistics, 24, 173-193.

[18] J. Van Hell \& T. Dijkstra (2002). Foreign language knowledge can influence native language performance in exclusively native contexts. Psychonomic Bulletin \& Review, 9, 780-789.

[19] A. Hernandez , P. Li \& B. MacWhinney (2005). The emergence of competing modules in bilingualism. Trends in Cognitive Sciences, 9, 220225.

[20] J. F. Kroll \& E. Bialystok (2013). Understanding the consequences of bilingualism for language processing and cognition. Journal of Cognitive Psychology, 25, 497-514.

[21] R. Amelia (2016). Benefits of Early Second Language Acquisition. Indonesian Journal of Integrated English Language Teaching, 2(1), 19-30.

[22] E. Bialystok (1997). Effects of Bilingualism and Biliteracy on Children's Emergent Concepts of Print. Developmental Psychology, 30 (3): 429-440.

[23] W. P. Thomas (1993). Academic Achievement 
Through Japanese, Spanish, or French: The First Two Years of Partial Immersion. Modern Language Journal , 77 (2): 170-180.

[24] E. A. Rafferty (1986). Second Language Study and Basic Skills in Louisiana. Baton Rouge, LA: Louisiana State Department of Education

[25] Cooper, T. C. (1987). Foreign Language Study and SAT-Verbal Scores. Modern Language Journal , 71 (4): 381-387.

[26] P.M. Lightbown and N. Spada (1999). How languages are learned. Oxford, OUP.

[27] Al Ghazali Fawzi. (2006). First Language Acquisition Vs Second Language Learning: What Is the Difference? The University of Birmingham / The Centre for English Language Studies (CELS).

[28] W.E. Lambert (1975). Culture and language as factors in learning and education. In Wolfgang A. (Ed.), Education of immigrant students. Toronto: Ontario Institute for Studies in Education.

[29] W.E. Lambert (1977). The effects of bilingualism on the individual: Cognitive and socio-cultural consequences. In Hornby P.A. (Ed.), Bilingualism: Psychological, social and Educational implications. New York: Academic.

[30] W.E. Lambert (1981). Bilingualism and language acquisition. In Winitz H. (Ed.), Native language and foreign language acquisition. New York: New York Academy of Science.

[31] Fillmore, L. W. (1991). When learning a second language means losing the first. Early childhood research quarterly, 6(3), 323-346.

[32] Ingles, 1. E. I. (2010). Advantages and disadvantages that kids have at the time they are learning english as a foreign language to become bilingual. 